\title{
Kaposi sarkomunda gastrik tutulum ve Helicobacter pylori
}

\section{Gastric involvement and Helicobacter pylori in Kaposi's sarcoma}

\author{
Aliye SOYLU ${ }^{1}$, Metin ÖZASLAN ${ }^{2}$, Aslı TURGUT ERDEMIR ${ }^{3}$, Büşra KARAHACIOĞLU², Özlem ALTUNTAŞ AYDIN ${ }^{4}$, \\ Serdal ÇAKMAK ${ }^{2}$, Fatih GÜZELBULUT ${ }^{2}$, Mehmet Salih GÜREL ${ }^{3}$ \\ Bakırköy Dr. Sadi Konuk Eğitim ve Araștırma Hastanesi, ${ }^{1}$ Gastroenteroloji Kliniğĭ, ${ }^{2}$ Dermatoloji Kliniğĭi, Istanbul \\ Istanbul Eğitim ve Araștırma Hastanesi, ${ }^{3}$ Dermatoloji Kliniği, Istanbul \\ Haseki Ĕgitim ve Araştırma Hastanesi, ${ }^{4}$ Klinik Mikrobiyoloji ve Enfeksiyon Hastalklan Kliniğ̈i, Istanbul
}

Giriş ve Amaç: Kaposi sarkom sıklıkla cilt bulguları ile ortaya çıkar. Gastrointestinal sistem nadiren tutulduğu için endoskopistler gastrik lezyonlara aşina değildir. Bu çalışmada klasik Kaposi sarkomu ve kazanılmış immün yetmezlik sendromu ilişkili Kaposi sarkomu olgularımızı gastrik semptomlar, gastrik tutulum ve Helicobacter pylori enfeksiyonu birlikteliği açısından değerlendirmeyi amaçladık. Gereç ve Yöntem: Kaposi sarkomu tanısı ile takip edilen 18 olgu çalışmaya dahil edildi. Kontrol grubu olarak polikliniğe başvuran ve Helicobacter pylori açısından test edilen 40 olgu çalışmaya dahil edildi. Kaposi sarkomlu tüm olguların evreleri, aldıkları tedaviler, cilt ve oral muayenesi kaydedildi. Olguların gastrik yakınmalannın olup olmadığı sorguland. Tüm olgulara gastroduodenoskopi yapıldı. Histopatolojik olarak gastrik tutulum alanlarından, ayrıca Helicobacter pylori birlikteliği açısından biyopsiler alındı ve kontrol grubu ile karşılaştırıldı. Bulgular: Kaposi sarkomlu 18 olgunun \%94,4'ü (n=17) erkek ve yaş ortalaması 59,3 (39-79) idi. Olguların 15'i $(\% 83,3)$ klasik Kaposi sarkomu, 3’ü $(\% 16,7)$ kazanılmıs immün yetmezlik sendromu ile ilişkili Kaposi sarkomu idi. Endoskopik olarak Kaposi sarkomu tanısı olan 5 olgudan 3'ünde tanı histopatolojik olarak dogrulandı. Kaposi sarkomu tanisı konan olgulardan 2'sinde fundus-korpus, l'inde ise antrum tutulumu vardı. Gastrik lezyon bulunmayan bölgelerden alınan biyopsilerde Kaposi sarkomu ile ilişkili patoloji saptanmadı. Tüm Kaposi sarkomlu olguların 10'u (\%55,6), gastrik tutulumlu Kaposi sarkomlularnn 2'si $(\% 66,6)$ ve gastrik tutulum olmayanların 8'i $(\% 55,3)$ semptomatik idi. Tüm Kaposi sarkomlu olgularin \%66,6'sinda Helicobacter pylori (+) idi. Kontrol grubunda ise Helicobacter pylori (+)'liği \%52,5 idi $(p=0,206)$. Gastrik tutulumlu olan Kaposi sarkomlu hastalardan 2'sinde Helicobacter pylori (+)'idi ve bu hastalar genç, oral tutulumlu ve kazanılmış immün yetmezlik sendromu ilişkiliydi. Sonuç: Gastrik semptomların varlığı gastrointestinal Kaposi sarkomu tanısı için yeterli değildir. Oral tutulumu olan olgularda gastrik tutulum daha sıktır. Gastrik tutulum kazanılmış immün yetmezlik sendromu ile ilişkili Kaposi sarkomunda daha sıktır. Helicobacter pylori (+)'liği açısından Kaposi sarkomu olan ve olmayan olgular arasinda fark yoktur.

Anahtar kelimeler: Kaposi sarkomu, gastrik lezyon, Helicobacter pylori

\section{GIIRIS}

Kaposi sarkomu (KS) immünolojik, infeksiyoz ve neoplastik süreçlerin birlikteliğinde ortaya çıkan, sıklıkla deriyi multisentrik tutan ve düşük malign potansiyeli olan vasküler kö-
Background and Aims: Kaposi's sarcoma usually presents as skin lesions. Since the gastrointestinal tract is rarely involved in Kaposi's sarcoma patients, endoscopists are not familiar with gastric lesions. In the present study, we aimed to evaluate patients with classical Kaposi's sarcoma and acquired immunodeficiency syndrome -associated Kaposi's sarcoma with respect to gastric symptoms, gastric involvement, and the presence of Helicobacter pylori. Materials and Methods: This study included 18 patients with Kaposi's sarcoma. Forty patients, admitted to the outpatient clinic for Helicobacter pylori, were included as the control group. Stage of the disease, therapy, and dermatological and oral examination findings were recorded. All patients were questioned regarding gastric symptoms and underwent upper gastrointestinal endoscopy. Biopsies were taken from areas suspected as having Kaposi's sarcoma involvement and from the corpus and antrum for the presence of Helicobacter pylori, and results were compared with the control group. Results: Among the 18 patients included in the study, 17 (94.4\%) of them were male, and the mean age of the patients was 59.3 (39-79) years. Fifteen patients (83.3\%) had classical Kaposi's sarcoma, while 3 (16.7\%) had acquired immunodeficiency syndrome -associated Kaposi's sarcoma. Of the 5 patients suspected of having Kaposi's sarcoma on upper gastrointestinal endoscopy, the diagnosis of Kaposi's sarcoma was verified in 3 patients histopathologically. The fundus and corpus were involved in 2 patients and the antrum in 1 patient. None of the biopsies taken from areas other than gastric lesions had any findings associated with Kaposi's sarcoma. In general, 10 patients $(55.6 \%)$ were symptomatic. Two of $3(66.6 \%)$ patients with gastric involvement and 8 of $15(55.3 \%)$ patients without gastric involvement were symptomatic. Helicobacter pylori was positive in $66.6 \%$ of all patients with Kaposi's sarcoma and in $52.5 \%$ of patients in the control group ( $p=0.206)$. Two patients with Kaposi's sarcoma and gastric involvement were positive for Helicobacter pylori, and these patients had oral involvement as well as acquired immunodeficiency syndrome -associated Kaposi's sarcoma, and they were younger. Conclusions: Presence of gastric symptoms was not enough to assume gastric involvement in Kaposi's sarcoma patients. Gastric involvement is more frequent in patients with oral involvement and in those with acquired immunodeficiency syndrome -associated Kaposi's sarcoma. There was no difference between patients with and without Kaposi's sarcoma in terms of Helicobacter pylori positivity.

Keywords: Kaposi's sarcoma, gastric lesion, Helicobacter pylori

kenli nadir tümörlerdir. Vasküler endotel ve perivasküler bağ dokusu hücrelerinin proliferasyonundan gelişen tümörler, sıklıkla immünsuprese hastalarda multifokal olarak saptanır- 
lar. Deri lezyonları KS'li tüm vakaların \%90'ında, çoğunlukla deri ve alt ekstremitelerde görülmekle birlikte vücutta birçok yerde de görülür. Ekstrakütanöz KS en sık lenf düğümleri, akciğerler ve gastrointestinal sistemde (GIS) görünür. GIS'te en sık mide tutulur (1-5). Kazanılmış immun yetmezlik sendromlu [Acquired Immuno Deficiency Syndrome (AIDS)] olgularda antiretroviral tedavinin yaygın kullanımı öncesinde, ilk tanı sırasında GIS tutulumunun yaklaşı \% 40 , otopsilerde ise \%80 olduğu bildirilmiştir. GIS tutulumu sistemik seyirli KS olgularının yaklaşık \%50'sinde hastalığın erken dönemlerinde görülebilir ve cilt tutulumu yokluğunda da gastrointestinal lezyonlarla ortaya çıkabilir (5-7). GIS'te oral, özofagus, mide, ince bağırsak ve kolon tutulumları bildirilmiştir (8). Gastrik tutulumlu hastalar çoğunlukla asemptomatik olmakla birlikte, en sık epigastrik ağrl, GIS kanama $(3,9)$, apandisit (10) bulguları saptanan vaka bildirimleri mevcuttur.

Gastrik tutulumlu olguların siklıkla asemptomatik olmasından veya spesifik cilt lezyonu olmadan da gastrik tutulum bulunabileceğinden endoskopi endikasyonlarını KS'de belirlemek zordur. Ayrıca KS'de GISS tutulumu hastalığın yayılımına bağlı tedaviyi planlamak açısından önemlidir. Ek olarak GIS lezyonlarının ciddi komplikasyonlara neden olabildiği de bilinmektedir. Çalışmamızda olgularımızın gastrik semptomlarını, endoskopik gastrik bulgularını veya tutulumunu, Helicobacter pylori (H. pylori) enfeksiyonu birlikteliğini klasik Kaposi sarkomu (KKS) ve AIDS ilişkili KS'de değerlendirmeyi amaçladık.

\section{GEREÇ VE YÖNTEM}

Hastanemizin ve farklı hastanelerin cildiye ve enfeksiyon kliniklerinde KS tanısı ile takip edilen 18 hasta çalışmaya dahil edildi. Hastaların l'i kadın, 17'si erkek olup, veriler prospektif olarak gözden geçirilmiştir. Tüm olguların hastalık evreleri, aldıkları spesifik veya son bir yıl içindeki farklı tedaviler, cilt muayene bulguları, gastrik yakınmaları sorgulanarak kaydedildi. GIS tutulumu açısından oral muayene yenilendi. Ayrıca polikliniğimize farklı nedenler ile başvuran ve $H$. pylori'si bakılan 40 olgu, kontrol grubu olarak çalışmaya alındı.

Tüm olgulara ve kontrol grubuna en az 8 saatlik açlık ve topikal \%10'luk lidokain ile farengeal anestezi sonrası üst GIS endoskopi yapıldı. KS'nin gastrik tutulumu açısından araştırıldı. Histopatolojik değerlendirme için spesifik lezyonları olan ve olmayan alanlardan multifokal biyopsiler alındı. H. pylori varlığı veya yokluğu; hem hızlı üreaz testi hem de histopatolojik inceleme sonucuna göre değerlendirildi. Hastaların verileri KKS'li ve AIDS ilişkili hastalarda karşılıklı değerlendirildi.

\section{İstatistiksel Değerlendirme}

Bu çalışmada istatistiksel analizler NCSS (Number Cruncher Statistical System) 2007 Statistical Software (Utah, USA) paket programı ile yapılmıştır.
Verilerin değerlendirilmesinde tanımlayıcı istatistiksel metotların (ortalama, standart sapma, sıklık dağılımları, yüzde dağllımları) yanı sıra ikili grupların karşılaştırmasında bağımsız t testi, nitel verilerin karşılaştırmalarında ki-kare testi kullanılmıştır. Sonuçlar, anlamlılık p<0,05 düzeyinde değerlendirilmiştir.

\section{BULGULAR}

KS'li 18 olgunun \%94,4'ü (n=17) erkek, \%5,6'sı (n=1) kadındı. Olguların yaş ortalaması 59,3 (39-79) idi. KKS'li olgular \%83,3 (n=15), AIDS ilişkili olgular ise \%16,7 (n=3) idi. Tüm KS'li olguların \%55,6 (n=10)'sında gastrik semptomlar vardı. Gastrik tutulumlu KS'lilerin 2'sinde $(\% 66,6)$ semptom var iken; gastrik tutulum olmayanların (n=15) \%55,3'ünde semptom vardi. Oral mukoza tutulumlu 3 olguda da gastrik tutulum mevcuttu. Bu 3 olgunun 2'sinde gastrik yakınma eşlik etmekteydi. Bir olguda belirgin reflü semptomları ve endoskopide reflü özofajit (LA-B) mevcuttu. Diğer olguda ise bulbusta aktif ülser ve uyumlu semptomları mevcuttu. Olguların son bir yıl içinde KS veya farklı bir hastalık nedeniyle herhangi bir ilaç, antibiyotik ve proton pompa inhibitörü (PPI) kullanımı yoktu.

Endoskopik KS tanısı olan 3 hastada tanı biyopsi ile doğrulandı. GIS endoskopik bulgularının yerleşimi; 2 olguda fundus-korpus, 1 olguda da antrumda idi. Ayrıca endoskopik görüntülerinde olası KS tanısı düşünülen 2 olguda biyopsi tanıyı desteklememiştir. Gastrik lezyon bulunmayan bölgelerden alınan biyopsilerde KS ile ilişkili patoloji saptanmadı.

Tüm KS'li olguların \%66,6'sında H. pylori (+)'di. Kontrol grubunda ise H. pylori (+)'liği \%52,5'di. Kontrol grubu ve KS'li grup arasında $H$. pylori varlığı dağılımları açısından farklılık yoktu ( $\mathrm{p}=0,206)$. Fakat KS grubunda $H$. pylori (+)'liği riski kontrol grubundan 2,17 kat fazla bulunmuştur. Gastrik KS tanılı 2 genç olgu H. pylori (+), oral tutulumlu ve AIDS ilişkiliydi.

\section{TARTIŞMA}

KS'nin klinik özellikleri ve histopatolojik bulguları benzer olan, klasik, endemik (Afrika tipi), epidemik (AIDS ilişkili) ve ilaç ilişkili (organ nakli ilişkli) olarak dört farklı alt tipi vardır $(11,12)$. KKS sıklıkla 50 yaş üzerinde görülmektedir. Bizim olgularımızın çoğunluğu da orta yaş ve yaşlı grupta yer alan KKS'li erkeklerdi.

KKS'nin karakteristik cilt lezyonları genelde alt ekstremitelerde morumsu, kırmızımsı-mavi veya koyu kahverengi plak, makül veya nodüllerdir. Daha az sıklıkta yüz, üst ekstremiteler, gövde ve genital bölgede lezyonları da bulunabilir $(5,13)$. Olgularımızın cilt lezyonları özellikle alt ekstremite distalindeydi. Literatürde cilt lezyonları ekzofitik, ekimotik, keloidal, kavernöz, telenjiektazik, lenfanjiyom benzeri lezyonlar gibi 
farklı morfolojik görünümler tariflenmiştir $(14,15)$. Bizim olgularımızın deri lezyonlanı makül $(\% 77,8)$, nodül $(\% 72,2)$, plak $(\% 27,8)$ tiplerinde değerlendirildi.

KS'de ekstrakütanöz tutulum en sık ağız boşluğu, Gí ve solunum sistemidir. Nadiren hastalı̆̆ın başlangıcı sırasında ağız, GiS mukozası ve bölgesel lenf nodu da etkilenmiş olabilir (16-18). Genel olarak gastrointestinal/oral mukoza tutulumu hastaların $\leq \% 10^{\prime}$ unu etkiler iken, AIDS ilişkili olanlarda daha yaygındır (19-21). Olgularımızın ilk tanıları cilt lezyonları ile konmuş ve 15 'i stage I, 3'ü oral tutulumu olan stage IV hastalardı. GIS tutulumu genellikle asemptomatik olmakla birlikte kanama, ishal, protein kaybettiren enteropati, invajinasyon ve perforasyon vakaları bildirilmiştir (16-18). Bizim serimizde gastrik tutulumlu KS olgularımızın \%66,6'sinda semptom var iken gastrik tutulum olmayanların $\% 55,3$ 'ünde semptom vardı. GIS semptomlarının varlı̆̆ı veya yokluğu gastrik KS öngörüsünde yararlı olmamakla birlikte, endoskopi öncesi klinik faktörlere dikkat edilmesi gerektiği bildirilmektedir (22). Gastrik tutulumlu olgularımız KS'nin gastrik tutulumuna ait farklı semptom göstermemekteydi. Semptomatik olanlardan birinde reflü ve diğerinde ise peptik ülser saptanmış olup, bu hastalıklara özgü semptomlar mevcuttu. KS ile ilişkili gastrik semptomların eşlik etmediği olgularımızda gastrik tutulum saptanması ile tedavi protokollerinin değişstirilmesi planlanmıştır.

Oral tutulum genellikle GIS tutulum ile korelasyon göstermektedir. Hastaların \%30'dan fazlasında oral kavitede yumuşak ve sert damak, gingiva veya tonsil üzerinde pigmente, yutmaya engel olacak tümöral lezyonların görüldüğü bildirilmiştir (5). Oral kavite tutulumu yaklaşık üçte bir olguda ortaya çıkabilir ve yaklaşık \% 15 'inde ilk belirtidir. Lezyonlarda ağr1, kanama, ülser veya sekonder enfeksiyon semptom ve bulguları olması da tedavi kararında önemlidir $(25,26)$. Olgularımızdan oral tutulumlu 3 olgunun oral semptomu yoktu ve gastrik KS tanısı mevcuttu. Daha önce belirtildiği gibi oral tutulum ile GIS korelasyonu bizim olgularımızda da mevcuttu (5). GIS lezyonları asemptomatik olabilir ya da kilo kaybı, karın ağrısı, ishal, bulantı, kusma, malabsorpsiyon, bağırsak obstrüksiyonu ve GIS kanama bulguları görülebilir $(6,27)$.

KKS'li 87 olgunun değerlendirildiği bir çalışmada olguların 71 (\%81,6)'inde gastrik lezyon saptanmıştır. Olguların 7l'inde de mide lezyon olup; mide lezyonlularda 19 özofagus, 8 proksimal duodenum, 2 özofagus ve duodenum yerleşimli ek lezyonlar bulunmuştur (23). AIDS ilişkili KS tanılı olguların \%5l'inde Gís'de lezyon saptanmış olup; \%15 olguda üst ve alt GiS'de, \%24 olguda sadece gastroduodenal lezyon ve \%12'sinde ise alt GiS'de lezyon saptanmıştır (24). Bu bulguların sıklığı KS hastalarında tarama endoskopisi yapılmasını ihtiyaç olarak düşündürse de asemptomatik GIS tutulumunun sıklığı muhtemelen prognoz üzerinde çok az etkisi olacağı görüşünü desteklemektedir. Uygulamada KKS'li olgu- larda semptom yok ise rutin endoskopi gerçekleştirilmez. Ayrıca 33 gastrik tutulumlu KS'lu hastalar ile 46 cilt tutulumlu KS hastaların GIS semptomları açısından karşılaştıııldığı bir çalışmada gastrointestinal semptomların varlığı gastrointestinal KS'u öngörmede yararlı bulunmamıştır (22). Bizim olgularımızdan GIS tutulumlu 3 olgumuzun l'i asemptomatikdi. Semptomatik bir olguda belirgin reflü semptomlarına eşlik eden reflü özofajit (LA-B), diğer olguda ise bulbustaki aktif ülseriyle ilişkli gastrik semptomlar mevcuttu. Gastrik tutuluma ait ek semptomlar yoktu.

Gastrointestinal KS'nin belirgin lezyonları daha önce tanı koymuş endoskopist tarafından kolayca tanınır $(28,29)$. Lezyonlar GIS'in herhangi bir bölümünde genellikle izole ya da birleşik yerleşimli hemorajik görünümlü nodüllerdir (30). Gastrik KS'nin endoskopik bulguları ise spesifik olup; belirgin kırmızı/mor renkli, vasküler görünümde ince mukoza ile kaplı submukozal nodüller sıklıkla görülür. Farklı olarak hemorajik yama tarzında mukozal kabarıklıklar, kırmızı papüler, krater tarzında polipoid lezyonlar da bildirilmiştir. Spesifik görüntülü lezyonlar mevcut ise biyopsi almak gerekmeyebileceği vurgulanmıştır $(23,29)$ Çünkü lezyonların submukozal olma eğilimi olduğundan biyopsi ile göstermek de mümkün olmayabilir $(30,31)$. Özellikle özofagus ve midedeki (küçük veya yama tarzındaki) lezyonlardan alınan biyopsilerde \%35,3 yalancı negatiflik olduğu da belirtilmiştir (32). Bizim hastalarımızın gastrik lezyonları iki hastada spesifik tipte multipl odaklı lezyonlardı (Resim 1-4). Diğer biri ise antrumda tek odakta geniş ve lümene protrüze polipoid kitle tarzındaydı. Parlak kırmızı-mor görünümlü mukozalı kabarik lezyonlardan alınan biyopsiler sonrası artmış hemoraji olması dikkat çekiciydi. Endoskopik spesifik KS görüntüye sahip 3 hastada tanı histopatolojik doğrulanmıştır. Fakat endoskopik 2 görüntüde KS’u olabileceği belirtilmiş olmasına rağmen, histopatoloji desteklemeyen 2 olgumuz mevcuttu. Muhtemel daha önce de literatürde belirtildiği gibi lezyonun submukozal yerleşimli olmasındandır. Ayrıca gastrik lezyon görülmeyen alanlardan alınan bulgularda KS'u ile ilişkli patoloji saptanmadı. Gastrik KS tanısı alanların 2'sinde (\%66,6) H. pylori (+) olup; 3'ünde oral tutulum vardı. Bu olgularm 2'si AIDS ilişkili ve yaşları daha gençti. Gastrik tutulumu olmayan hastaların ise \%71'inde H. pylori (+)'di.

KS'li olgularda H. pylori'yi araştıran çalışma olmamakla birlikte; bir çalışmada AIDS ilişkili vakalarda H. pylori sıklığının normal popülasyonla farkllılı göstermediği ve antiretroviral tedavi ile tedavi sonunda H. pylori yoğunluğunun arttığı bildirilmiştir (33). Bizim çalışmamızda da KS'li olgular ile kontrol grubu H. pylori varlığı dağılımları arasında farklılık yoktu. KS grubunda $H$. pylori (+) varlığı riski kontrol grubundan 2,17 kat fazla bulunmuştur.

Sonuç olarak; KS'li olgularda gastrik semptomların varlığ1 olası gastrointestinal KS tanısını düşündürmez. Gastrik KS'li 

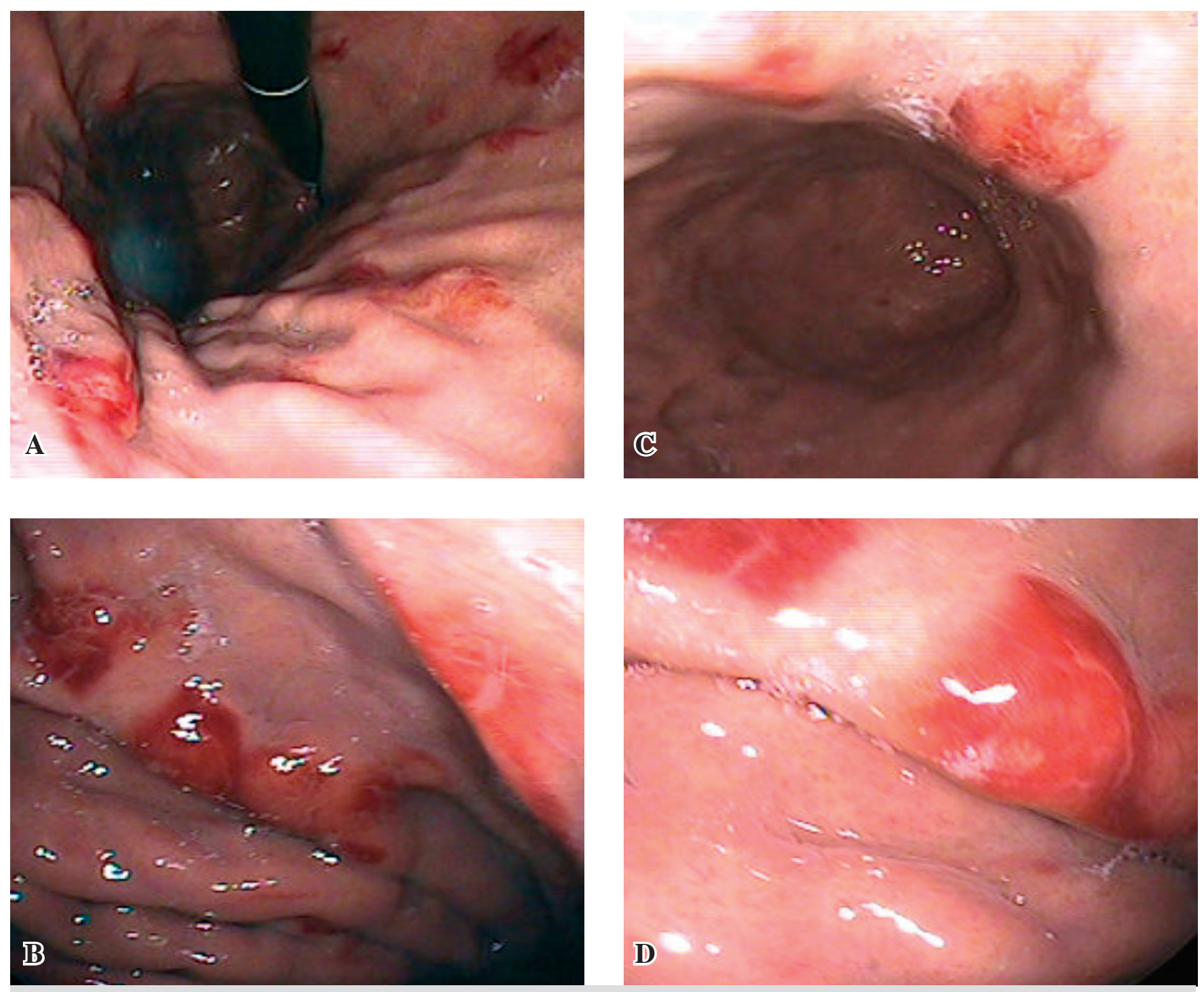

Resim 1. Iki farklı hastada (A) fundus, (B) korpus, (C) küçük kurvatura ve (D) antrum ön duvarda Kaposi sarkomu ile uyumlu lezyonlar.

olgularda sıklıkla semptom korelasyonu da yoktur. Fakat oral mukoza tutulumlu KS'li olgularda GiS tutulumu sıklı̆ı arttığından ve bu durum tedavi planını değiştireceğinden, endoskopik değerlendirme önerilmelidir. Bizim çalışmamızda gastrik tutulumun AIDS ilişkili grupta daha sık olduğu göz önüne alınır ise; AIDS ilişkili oral mukoza tutulumlu KS olgularına da endoskopi gerekmektedir. Ayrıca gastrik tutulumlu KS'lilerin asemptomatik de olabileceği unutulmamalıdır. $H$. pylori mevcudiyeti KS olan ve olmayan olgular arasında farklllık göstermemektedir.

\section{KAYNAKLAR}

1. Martin JN, Ganem DE, Osmond DH, et al. Sexual transmission and the natural history of human herpesvirus 8 infection. N Engl J Med 1998 338: 948.

2. Frances C. Kaposi's sarcoma after renal transplantation. Nephrol Dial Transplant 1998; 13: 2768-73.

3. Szende B, Thot A, Perner F, Nagy K. Clinicopathologic aspects of $8 \mathrm{Ka}$ posi's sarcomas among 1009 renal transplant patients. Gen Diagn Pathol 1997; 143: 209-13.

4. Balthazar EJ, Richman A. The radiology corner: Kaposi's sarcoma of the stomach. Am J Gastroenterol 1977; 67: 375-9.

5. Trubowitz PR, Volberding PA. Malignacies in human immunodeficieny virus infection. In: Mandell GL, Benett JE, Dolin R, eds. Principles and Practice of Infectious Diseases. 5th ed. Philadelphia: Churchill Livingstone 2000; 1439-49.

6. Laine L, Amerian J, Rarick M, et al. The response of symptomatic gastrointestinal Kaposi's sarcoma to chemotherapy: a prospective evaluation using an endoscopic method of disease quantification. Am J Gastroenterol 1990; 85: 959

7. Friedman SL, Wright TL, Altman DF. Gastrointestinal Kaposi's sarcoma in patients with acquired immunodeficiency syndrome. Endoscopic and autopsy findings. Gastroenterology 1985; 89: 102-8. 
8. Kahl P, Buettner R, Friedrichs N, et al. Kaposi's sarcoma of the gastrointestinal tract: report of two cases and review of the literature. Pathol Res Pract 2007; 203: 227-31.

9. Chapman SM, Bell SJ, Chen S, Cosolo W. Classical Kaposi's: a rare cause of gastrointestinal haemorrhage. J Gastroenterol Hepatol 1996; 11: 40810 .

10. Egwuonwu S, Gatto-Weis C, Miranda R, Casas Lde L. Gastrointestinal Kaposi sarcoma with appendiceal involvement. South Med J 2011; 104: 278-81.

11. Senba M, Buziba N, Mori N, et al. Increased prevalence of Kaposi's sarcoma-associated herpesvirus in the Kaposi's sarcoma-endemic area of western Kenya in 1981-2000. Acta Virol 2011; 55: 161-4.

12. Schwartz RA. Kaposi's sarcoma: an update. J Surg Oncol 2004; 87: 14651 .

13. Dezube BJ. Clinical presentation and natural history of AIDS-related Kaposi's sarcoma. Hematol Oncol Clin North Am 1996; 10: 1023-9.

14. Mohanna S, Sanchez J, Ferrufino JC, et al. Lymphangioma-like Kaposi's sarcoma: report of four cases and review. J Eur Acad Dermatol Venereol 2006; 20: 1010-1.

15. Ronchese F, Kern AB. Lymphangioma-like tumors in Kaposi's sarcoma. AMA Arch Derm 1957; 75: 418-27.

16. Balachandra B, Tunitsky E, Dawood S, et al. Classic Kaposi's sarcoma presenting first with gastrointestinal tract involvement in a HIV-negative Inuit male--a case report and review of the literature. Pathol Res Pract 2006; 202: 623-6.

17. Neff R, Kremer S, Voutsinas L, et al. Primary Kaposi's sarcoma of the ileum presenting as massive rectal bleeding. Am J Gastroenterol 1987; 82: $276-7$.

18. Weprin L, Zollinger R, Clausen K, Thomas FB. Kaposi's sarcoma: endoscopic observations of gastric and colon involvement. J Clin Gastroenterol 1982; 4: 357-60.

19. Stratigos JD, Potouridou I, Katoulis AC, et al. Classic Kaposi's sarcoma in Greece: a clinico-epidemiological profile. Int J Dermatol 1997; 36: 735-40.

20. Jaimovich L, Calb I, Kaminsky A. Kaposi's sarcoma of the conjunctiva. J Am Acad Dermatol 1986; 14: 589-62.
21. Cottoni F, Masala MV, Piras P, et al. Mucosal involvement in classic Kaposi's sarcoma. Br J Dermatol 2003; 148: 1273-4.

22. Nagata N, Shimbo T, Yazaki H, et al. Predictive clinical factors in the diagnosis of gastrointestinal Kaposi's sarcoma and its endoscopic severity. PLoS One 2012; 7 : e46967.

23. Kolios G, Kaloterakis A, Filiotou A, et al. Gastroscopic findings in Mediterranean Kaposi's sarcoma (non-AIDS). Gastrointest Endosc 1995; 42: 336-9.

24. Parente F, Cernuschi M, Orlando G, et al. Kaposi's sarcoma and AIDS: frequency of gastrointestinal involvement and its effect on survival. A prospective study in a heterogeneous population. Scand J Gastroenterol 1991; 26: 1007-12.

25. Francis HW. Head and neck manifestations of Human immundeficiency virus infections. In: Cummings CW, Fredrickson JM, Harker LA, et al. (eds). Otolaryngology-head and neck surgery. 3rd ed. St. Louis: Mosby; 1998; 289-91.

26. Nichols CM, Flaitz CM, Hicks MJ. Treating Kaposi's lesions in the HIVinfected patient. J Am Dent Assoc 1993; 124: 78-84.

27. Danzig JB, Brandt LJ, Reinus JF, Klein RS. Gastrointestinal malignancy in patients with AIDS. Am J Gastroenterol 1991; 86: 715-8.

28. Friedman SL, Wright TL, Altman DF. Gastrointestinal Kaposi's sarcoma in patients with acquired immunodeficiency syndrome. Endoscopic and autopsy findings. Gastroenterology 1985; 89: 102-8.

29. Chetty R, Pillay JV. Coexistent gastric MALT lymphoma and Kaposi's sarcoma in an HIV patient. J Clin Pathol 1999; 52: 313-6.

30. Ioachim HL, Adsay V, Giancotti FR, et al. Kaposi's sarcoma of internal organs. A multiparameter study of 86 cases. Cancer 1995; 75: 1376-85.

31. Szende B, Thot A, Perner F, Nagy K. Clinicopathologic aspects of 8 Kaposi's sarcomas among 1009 renal transplant patients. Gen Diagn Pathol 1997; 143: 209-13.

32. Nagata N, Sekine K, Igari T, et al. False-negative results of endoscopic biopsy in the diagnosis of gastrointestinal Kaposi's sarcoma in HIV-infected patients. Patholog Res Int 2012; 2012: 854146.

33. Nkuize M, De Wit S, Muls V, et al. Upper gastrointestinal endoscopic findings in the era of highly active antiretroviral therapy. HIV Med 2010; 11: 412-7. 